\title{
Uma análise preliminar da política de promoção da igualdade racial*
}

\section{A preliminary analysis of the promotion policy racial equality}

\author{
"A questão não é saber se um dado país está preparado para a \\ democracia, mas antes partir da ideia de que um país se prepara \\ através da democracia”. Amarthya Sen
}

Carlos Alberto Santos de Paulo’

\section{Resumo}

Este artigo faz uma breve análise dos desafios para implementação da Política de Promoção da Igualdade Racial para o enfrentamento das desigualdades raciais no Brasil a partir da institucionalização e consolidação da agenda pública. O qual se propõe refletir sobre os estigmas oriundos da escravidão e os desafios para se colocar o debate de cunho racial no campo do compromisso político e social do Estado brasileiro. Com ênfase nas relações do Estado e as demandas da sociedade civil, interessa analisar o grau de efetividade de uma política racial para além das ações pontuais das políticas sociais brasileiras a partir do recorte racial. Objetivando partir de uma breve análise quanto às perspectivas e impasses na consolidação da política de Promoção da Igualdade Racial, do ponto de vista da avaliação dos recursos, da magnitude dos gastos e da natureza das fontes de financiamento. Por fim trará algumas considerações acerca da compatibilidade entre os objetivos propostos no enfrentamento das desigualdades raciais por meio da Política de Promoção da Igualdade Racial, bem como abordará a pertinência das ações de governo na mitigação dessas desigualdades.

Palavras-chave: Racismo. Política de Promoção da Igualdade Racial. Estado. Sociedade.

\begin{abstract}
This article analyses briefly the challenges to implementing the Promotion of Racial Equality Policy to address racial inequalities in Brazil taking in account the institutionalization and consolidation of public agenda.
\end{abstract}

Keywords: Racism. Promotion of Racial Equality Policy. State. Society.

Recebido em 22 mar. 2012

Aprovado em 16 mai. 2012

1 Doutorando do Programa de Pós-Graduação em Política Social do Departamento de Serviço Social da Universidade de Brasília. Endereço eletrônico: albertos@ucb.br 


\section{Introdução}

O modelo de sociedade erigido no Brasil, do ponto de vista dos direitos, revela uma emblemática omissão histórica quanto às escolhas políticas de tratamento na incorporação do negro na sociedade em questão, no que tange ao mercado de trabalho e, efetivamente, às condições infraestruturais de uma sociedade de classes. Foram 355 anos de um modelo econômico com base na escravidão (1535-1888) que teve como sustentação o racismo estruturante das relações sociais brasileiras e que resultou em um quadro de desigualdades abissais para alguns segmentos populacionais, com ênfase para a população negra, como atestam os dados dos órgãos oficiais brasileiros.

A percepção de que o enfrentamento da desigualdade passa pela adoção de políticas direcionadas ao campo racial ainda é algo a ser construído. Os governos no pós-constituinte iniciaram um processo lento e ainda tímido de construção de uma área de atuação denominada promoção da igualdade racial. Esse parece ser o grande desafio, cujo efetivo enfrentamento poderá representar um salto qualitativo na consecução de uma sociedade mais igual e democrática.

Este artigo objetiva analisar preliminarmente os desafios e impasses da Política de Promoção da Igualdade Racial considerando que o enfrentamento das desigualdades que ainda grassam a realidade brasileira requer o aprimoramento das políticas públicas e dos mecanismos de proteção social. Nesse sentido, uma das áreas que deverão merecer maior atenção por parte do Estado e do governo é a área das desigualdades raciais.

Dessa forma, não se está aqui defendendo uma política social exclusiva para a população negra, todavia é fundamental que se faça uma análise quanto à efetividade das diretrizes universalizantes dos serviços públicos essenciais, tais como: educação, saúde, previdência, segurança e saneamento, dentre outros.

Para tanto, o presente artigo aborda quatro tópicos. O primeiro traz uma breve reflexão sobre os estigmas oriundos da escravidão e os desafios para se colocar o debate de cunho racial no campo do compromisso político e social do Estado brasileiro. O segundo tópico abordará o recorte racial da política social brasileira. O terceiro traça a agenda política do Estado brasileiro pautada pela temática racial. $\mathrm{O}$ quarto tópico fará uma breve análise das perspectivas e impasses na consolidação da políti- ca de Promoção da Igualdade Racial, do ponto de vista da avaliação dos recursos, da magnitude dos gastos e da natureza das fontes de financiamento. Por fim, o quinto tópico trará as considerações acerca da compatibilidade entre os objetivos propostos no enfrentamento das desigualdades raciais por meio da Política de Promoção da Igualdade Racial, bem como abordará a pertinência das ações de governo na mitigação dessas desigualdades.

\section{A política social no Brasil e os antecedentes do modelo econômico baseado na escravidão}

Ao lançarmos um olhar sobre o modelo da formação social brasileira, observamos a existência de mecanismos institucionais sutis, porém, com forte teor racial que reforçaram a existência de grupos tradicionalmente excluídos (mormente as populações negra e indígena) pautados por uma lógica colonial.

Os caminhos propostos pela lógica colonial - visto que o aparato jurídico brasileiro teve seu processo iniciado a partir da outorga da Constituição Política do Império do Brasil, em 25 de março de 1824, inspirada nas chamadas ordenações do Reino: as Ordenações Afonsinas (1446-1521); as Ordenações Manoelinas (1521-1603) e as Ordenações Filipinas (1603-1830) - estabeleceram desde sempre uma profunda aliança entre punição, propriedade e privilégios (SILVA JUNIOR, 2006).

Essa lógica colonial foi marcada por uma necessidade constante de se estabelecerem regras de controle aos africanos escravizados, bem como limitar a ascensão desse segmento, como categoria social. Isso, ao tempo em que garantia justificava a supremacia dos colonizadores e seus descendentes.

Em outras palavras, tais mecanismos negavam os problemas estruturais nas relações de acesso e convivência entre indivíduos, justificaram e procuraram manter a estrutura de poder e os privilégios de grupos sociais distintos tendo sua origem no período da colonização.

Sob a alegação de uma efetiva crença na neutralidade jurídica, os primórdios do pensamento jurídico brasileiro foram estruturados com base em regras de funcionamento que tomaram como ponto de partida as formulações encontradas pelos juristas e intelectuais da época para o trato com as questões de ordem social, negando radicalmente o componente racial. 
A relação intrínseca entre o modelo eugênico pretendido ${ }^{2}$ e os ideais nacionalistas com base na cultura europeia estiveram sempre estruturando a sociedade brasileira e estabelecendo as diretrizes para a consolidação de uma elite dominada pelo nascimento, pertencimento étnico-racial, nível hierárquico, sexo e riqueza material.

Por outro lado, a arqueologia do modelo civilizatório inaugurado aqui também se pautou pela lógica de uma nação híbrida na qual os ideais revolucionários da igualdade formal de cariz francesa se adequaria aos moldes universalistas de uma nação democrática racialmente falando e com características peculiares distintas de qualquer expressão existente nos países colonizadores. É como se os determinantes culturais transplantados pela língua, religião e imaginário estivessem dissociados das determinações políticas e econômicas de poder.

Nesse sentido, é indispensável trazer ao bojo das discussões o papel político fundamental que sedimentou uma ideia de democracia racial conjugada em paralelo com uma forte propaganda imigracionista para os trabalhadores desempregados da Europa Ocidental no início do século XX.

Esse estratégico movimento dual verificado pelas ações do Estado brasileiro enfunado pelos ventos modernizantes colonizadores, ao nosso entendimento, marca os ideais de formação das identidades nacionais preconizados pelo domínio político das elites e governos do período.

Essas considerações iniciais se devem ao fato de que ao tratarmos da difícil questão das relações raciais no Brasil e as demandas preconizadas pela relação Estado e sociedade e seus determinantes sociais, não se pode omitir ou negar as variantes históricas para uma compreensão mais realística das relações econômicas por meio da escravidão frente ao determinismo vigente até os dias atuais.

\footnotetext{
2 Nas primeiras décadas do século XX, houve a difusão de uma série de ideias acerca do que se chamou de "Eugenia". Criada no século XIX, por Francis Galton, a eugenia visava ao aprimoramento da raça humana pela seleção dos genitores, tendo como base o estudo da hereditariedade.. No Brasil, a eugenia foi em introduzida em 1914 na Faculdade de Medicina do Rio de Janeiro com a tese de Alexandre Tepedino. O $1^{\circ}$ Congresso Brasileiro de Eugenia, em 1929,objetivou a adoção de políticas governamentais de "higiene radical" e "políticas estatais colonizatórias e imigratórias". Preconizava-se uma nação homogênea e a criação de um "tipo racial" brasileiro "eugenicamente" mais branco.
}

O Estado moderno brasileiro forjado às nascentes idealizações das revoluções burguesas teve seu corolário constituído pelos seguintes ideários liberais: uma soberania popular assegurada por regime político representativo, a separação dos poderes, a supremacia das leis com sujeição do Estado, a legalidade e a igualdade reconhecida no plano formal.

Nesse sentido, sua concepção, enquanto lócus de poder, esteve assentada nas liberdades públicas asseverando os valores individualistas, que a rigor, colocavam limites à democracia e, ao mesmo tempo, consagravam uma ordem institucional abertamente excludente.

É a partir da Constituição Federal de 1988 (CF/1988) que se redimensiona o marco no que tange à atuação governamental no âmbito social. Observa-se uma nova postura do Estado em face das questões importantes, elegendo prioridades que culminaram por dotar o país finalmente de uma estrutura de proteção social.

Os princípios emanados nessa Constituição trataram de dar eficácia aos direitos e garantias fundamentais, consubstanciados nos direitos sociais, desvinculando esses direitos do modelo econômico, efetivando um modelo securitário de política pública independente da lógica de mercado.

De fato, a naturalização da desigualdade em nosso país está, em grande medida, associada à existência do racismo e de seus desdobramentos: o preconceito e a discriminação racial. A sociedade brasileira convive com uma desigualdade com notório viés racial. A população negra é a que está mais afeta à situação de pobreza e de miséria e aos percalços sociais daí decorrentes: desemprego, informalidade, piores condições habitacionais e de infraestrutura, acesso à educação e saúde, dentre outros.

Com o advento da Constituição de 1988, ampliase a perspectiva de construção de um padrão público universal de proteção social, conforme assinalam Behring e Boschetti (2006). Evidentemente, essa conformação não significou a superação das mazelas sociais anteriores, mas representou a efetivação do resgate do papel social do Estado.

Consubstanciado no âmbito das normas centrais as quais se situam entre os princípios fundamentais e os preceitos relacionados à ordem social, o art. 194 define a seguridade social como o "[...] conjunto integrado das 
ações de iniciativa dos poderes públicos e da sociedade, destinado a assegurar os direitos relativos à saúde, à previdência e à assistência social” (CF, 1988).

O conceito de seguridade social introduzido pela Constituição Federal tem como objetivo primeiro a universalidade da cobertura e do atendimento. Essa inovação representou o resgate da cidadania para milhões de brasileiros vivendo em situação de penúria e de ausência da ação do Estado. Trata-se, portanto, de uma perspectiva de efetiva inclusão social trazida pela nova Carta Magna, na qual a própria ideia de seguridade social aparece como um dos principais instrumentos. Seus princípios institucionais estão delineados a partir de um valor absoluto na consecução dos três eixos, a saber:

a) Universalidade de Cobertura e Atendimento - a universalidade rege hierarquicamente os demais princípios, ao garantir a todas as pessoas, em tese, os mínimos sociais, considerada a situação social prevista;

b) Uniformidade e Equivalência das Prestações - os benefícios e serviços devem ser idênticos para toda a população, sem distinção urbana ou rural, independentemente da residência, local de trabalho, profissão ou função ou valor e tipo de prestação e;

c) Seletividade e Distributividade - o princípio da seletividade e da distributividade é o mais complexo da seguridade, porque contrapõe a ponderação das desigualdades reais (equidade) ao princípio da igualdade formal (universalidade).

\section{0 recorte racial da política social brasileira}

Ao tratar da pobreza em um país marcado por séculos de escravidão, é indissociável a combinação histórica do desenvolvimento econômico e as relações entre Estado e uma sociedade marcada pelo ideário escravista persistente na mentalidade da jovem nação, ao tempo em que, na Europa ocidental, o sistema capitalista passava por profundas transformações no âmbito dos aspectos financeiro e industrial no século XIX.
O debate em torno das políticas sociais mais recentemente vem suscitando um maior aprofundamento de análise quanto ao processo histórico da formação do Brasil. Não obstante os indicadores sociais marcados por desigualdades abissais entre as classes, as dimensões de lutas específicas protagonizadas por segmentos da população negra e de mulheres vêm ganhando destaque. Nesse sentido, as dimensões de raça e gênero passaram a ter relevância em face de um contundente e expressivo distanciamento dos indicadores sociais quando analisados pelos recortes supracitados.

Sendo assim, a universalização dos serviços públicos, mesmo com os atuais arranjos institucionais, não tem ainda promovido o alcance ideal de desenvolvimento nacional, levando-se em consideração a diversidade propugnada pela dimensão étnico-racial e de gênero.

Discutir a política social no momento atual implica buscar esclarecimentos quanto aos processos, as intenções, o contexto e as circunstâncias em que se constituiu a historicidade das etapas da moderna ideia de democracia social no Brasil; não se pode tomar realidades presentes como se fossem episódios trans-históricos que se encerram em si a despeito das interpretações do passado e reflexos no presente.

Para efeito de localização e delimitação do tema em tela, a relação que se faz entre política social, pobreza e raça se deve ao fato de que, no Brasil, conforme afirmam Paixão e Carvano (2008), a pobreza tem cor. A principal causa da incidência da pobreza junto à população negra se deve à persistência do preconceito, da discriminação racial e do racismo. Asseveram ainda os supracitados autores: “[...] as mazelas, certamente, se associam à discriminação social, entretanto, não se esgota e nem as resume" (PAIXÃO; CARVANO, 2008, p.18).

No entanto, tal bandeira não é contraditória com a causa dos que anseiam pela promoção da equidade racial no Brasil. Isso pelas seguintes razões:

I) Foram os negros de ambos os sexos os mais prejudicados pelo caráter restrito e insuficiente das políticas sociais ao longo da história brasileira;

II) A exclusão de um contingente proporcionalmente maior de negros na definição das políticas sociais não foi produzida espontaneamente, mas, sim motivada por um entranhado racismo institucional que considerava indesejável a presença afro-descendente na sociedade; 
III) A aplicação momentânea de recursos relativamente mais concentrada em um determinado contingente da população historicamente discriminado não necessariamente se contrapõe à perspectiva de universalização dos serviços sociais e a progressiva melhoria dos indicadores sociais em geral (PAIXÃO; CARVANO, 2008, p.19).

\section{Agenda política do estado brasileiro e a polí- tica de promoção da igualdade racial}

A partir de 1995, com a realização da $1^{\text {a }}$ Marcha Zumbi dos Palmares contra o Racismo, pela Cidadania e a Vida, houve a consolidação efetiva de uma pauta política formal protagonizada pelo movimento social negro brasileiro.

A institucionalização do tema pode ser atribuída, inicialmente, a vários fatores, como o lento processo de incorporação dos debates no âmbito da esquerda; a relutância cultural do país em admitir que fora erigido sob pilares euro-etnocêntricos; a negação e/ou omissão da historiografia brasileira quanto ao passado escravocrata, dentre outros aspectos igualmente potenciais da invisibilidade das desigualdades entre negros e brancos.

A política de igualdade racial, nos últimos anos, vem ocupando significativos espaços de debate nos meios acadêmicos, nas empresas, e nas agendas governamentais e legislativas. Fruto de uma intermitente luta do movimento negro brasileiro, esse processo tem sido lento e não isento de contradições, muitas delas advindas da própria maneira com que as expressões da luta de enfrentamento do racismo e suas variadas formas discriminatórias são percebidas pelo próprio movimento e a população negra do país.

No entanto, já se podem observar avanços quanto à compreensão do fenômeno do racismo enquanto um poderoso elemento estruturante das relações sociais, políticas e culturais e seus impactos mais gerais para a consolidação da democracia e equidade. Todavia, apesar do forte apelo que o tema enseja na consagração de processos emancipatórios, ainda é corrente as dificuldades de uma efetiva integração dessa pauta no âmbito das formulações das políticas.

No que concerne às ações governamentais, podese elencar um conjunto significativo de ações que expres- sam o vigor dos debates e suas respectivas respostas formais, a saber: 1 - a realização da III Conferência Mundial contra Racismo, Discriminação Racial, Xenofobia e Intolerância correlata, em 2001; 2 - programas e ações relativas à promoção da igualdade racial foram criados em alguns ministérios entre 2001 e 2002; 3 - em 2003, com a vitória do PT nas eleições presidenciais, o programa do Partido Brasil sem Racismo, será a base teórica para a criação da Secretaria Especial de Políticas de Promoção da Igualdade Racial (SEPPIR); 4 - o Conselho Nacional de Promoção da Igualdade Racial (CNPIR) e do Fórum Intergovernamental de Promoção da Igualdade Racial (FIPIR) são criados.

Destaque se a consolidação de um importante instrumento de controle social que foi a realização da I e II Conferências Nacionais de Promoção da Igualdade Racial (CONAPIR), as quais definiram as diretrizes para a elaboração de planos setoriais para a população negra: I) Plano Nacional de Implementação da Lei no ${ }^{\circ} 10.637 / 2003$; II) Plano Nacional de Saúde Integral da População Negra; III) Agenda Social Quilombola e Programa Brasil Quilombola.

De acordo com Nota Técnica n. 07 do Instituto de Pesquisa Econômica Aplicada (IPEA):

No entanto, a política de igualdade racial em curso ainda não conseguiu alçar essa temática à centralidade das estratégias de desenvolvimento nacional. $\mathrm{O}$ fortalecimento da política depende em nível estratégico de mais apoio político, de forma a reposicioná-la como condicionante para o alcance do ideal nacional de justiça social e, complementarmente, em nível tático e operacional, é essencial que os mecanismos de planejamento e orçamento sejam coordenados de forma a considerar suas especificidades e apoiar sua adoção ativa pelos diversos campos de atuação governamental (SILVA, 2011, p. 3).

Destarte, no processo de consolidação dessas ações governamentais é fundamental a análise dos aspectos essenciais da política de promoção da igualdade racial no que concerne à reafirmação do compartilhamento das responsabilidades entre os diversos órgãos governamentais na implementação dessas políticas, bem como dar maior visibilidade às estratégias de planejamento e financiamento do órgão coordenador - Secretaria de Políticas de Promoção da Igualdade Racial (SEPPIR) - e demais membros institucionais da esfera governamental. 


\section{Perspectivas e impasses na consolidação da política de promoção de igualdade racial}

A fragmentação e as fragilidades com que se vêm traduzindo as ações governamentais na consolidação dos processos de planejamento e gestão da referida política revelam ambiguidades. Por um lado, quanto ao reconhecimento da existência das desigualdades raciais no Brasil e pela identificação destas desigualdades como o cerne da problemática racial brasileira. Por outro, não se percebe uma efetiva disposição de fazer enfrentamento do tema mediante mecanismos institucionais por meio de políticas públicas dotadas de um conjunto organizado, sistemático e coordenado de iniciativas articuladas intersetorialmente.

Diante do quadro, as questões do financiamento das ações e da definição de estratégias para assegurar recursos nos diferentes ministérios e secretarias têm se constituído em critérios de cunho carismático sem uma clara atribuição formal institucional e sem definição de previsão e execução orçamentária de cada ação.

Para uma melhor explicitação dos obstáculos observados nos processos de planejamento setoriais da política em tela, observemos os mecanismos balizadores da ação do Estado. Segundo a Constituição Federal, art. 65, as linhas mestras da ação governamental federal, no Brasil, devem estar expressas nos seguintes instrumentos: $\mathrm{O}$ Plano Plurianual (PPA); a Lei de Diretrizes Orçamentárias (LDO); e a Lei Orçamentária Anual (LOA).

Esses mecanismos institucionais respondem por um complexo conjunto de objetivos conformando o sistema de planejamento do Poder Executivo e devendo ser submetido à aprovação do Congresso Nacional.

O PPA tem duração quadrienal. O atual, já em sua etapa final, compreende o período 2003 -2007. Lá estão as principais linhas de ação governamental, que, no caso, foram estabelecidas a partir da definição de três megaobjetivos:

a) Mega-objetivo 1: inclusão social e redução das desigualdades sociais;

b) Mega-objetivo 2: crescimento com geração de emprego e renda, ambientalmente sustentável e com redução das desigualdades regionais e;

c) Mega-objetivo 3: promoção e expansão da cidadania e fortalecimento da democracia.
Cada um dos mega-objetivos foi decomposto em desafios. Ao todo foram estabelecidos 31 desafios, dentre os quais, o de $n^{\circ} 8$, ligado ao Mega-objetivo 1, que interessa mais de perto a este trabalho: “[...] promover a redução das desigualdades raciais, com ênfase na valorização cultural das etnias". O desafio 8 apresenta os seguintes desdobramentos em termos de diretrizes:

a) Definir políticas direcionadas para a redução das desigualdades raciais, ao combate à discriminação e ao preconceito racial;

b) Promover políticas de ação afirmativa;

c) Promover a equalização do acesso aos serviços públicos e aos direitos sociais básicos, tendo em vista o corte racial;

d) Apoiar, ampliar e aperfeiçoar a cogestão, parcerias e controle social com as organizações da sociedade civil;

e) Envolver a população, grupos vulneráveis e organizações na elaboração das políticas e implementação dos projetos e;

f) Implementar políticas de promoção que garantam a igualdade racial e condições de trabalho iguais independentemente de raça e estrato social.

O segundo balizador, a LDO, também tem suas atribuições definidas no texto constitucional; deve apresentar as metas e prioridades anuais da administração pública federal; orientar a elaboração da lei orçamentária anual; dispor sobre as alterações na legislação tributária; e estabelecer a política de aplicação das agências financeiras oficiais de fomento (CF, art. $165 \$ 20)$. É a LDO, portanto, que vai estabelecer as bases da Lei Orçamentária do ano seguinte, funcionando como uma espécie de elo entre o PPA e o Orçamento.

Tomando-se o exemplo da LDO sancionada em dezembro de 2006, tem-se, em seu art. 1 o o seguinte:

São estabelecidas, em cumprimento ao disposto no art. 165, §2o, da Constituição, e na Lei Complementar no 101, de 4 de maio de 2000 , as diretrizes orçamentárias da União para 2007, compreendendo:

I - as prioridades e metas da Administração Pública Federal; 
II - a estrutura e organização dos orçamentos;

III - as diretrizes para a elaboração e execução dos Orçamentos da União e suas alterações;

IV - as disposições relativas à dívida pública federal;

$\mathrm{V}$ - as disposições relativas às despesas da União com pessoal e encargos sociais;

VI - a política de aplicação dos recursos das agências financeiras oficiais de fomento;

VII - as disposições sobre alterações na legislação tributária da União;

VIII - as disposições sobre a fiscalização pelo Poder Legislativo e sobre as obras e serviços com indícios de irregularidades graves; e

IX - as disposições gerais. (BRASIL, 2006)

Tem-se assim, com a LDO, o roteiro básico a ser seguido pela Lei Orçamentária Anual (LOA).

A LOA é, de fato, a peça orçamentária na qual estão previstos os programas e as ações, assim como os desembolsos respectivos. Lá estão inscritas, de fato, as prioridades do governo. De acordo com a Constituição Federal, o orçamento deve ser desmembrado em três: o orçamento fiscal; o orçamento de investimento das empresas; e o orçamento da seguridade.

$\mathrm{Na}$ prática, apenas os dois primeiros orçamentos existem de fato. Já o terceiro, referente à seguridade social, em função da própria segmentação, independência e autonomia das três áreas que o compõem (saúde, assistência social e previdência social), tem uma existência meramente contábil, o que certamente vem desvirtuar a perspectiva de política social inscrita na Carta Magna. De todo modo, a LOA estabelece o horizonte e os limites da ação governamental, assim como suas prioridades e perspectivas.

Para um balizamento dessa análise, Theodoro (2011, p. 9) assevera:

Com efeito, nesses três anos de vigência do PPA 2003-2007, o que se pode observar é que, de um modo geral, a despeito das diretrizes anuais inscritas nas respectivas LDO, as ações propostas nas LOA, no que tange à problemática racial, têm sido pontuais e as metas a elas associadas não se colocaram efetivamente à altura do desafio de "reduzir as desigualdades raciais no país". No caso do Programa "Gestão da Política de Promoção da Igualdade Racial", governo disponibilizou, anualmente, menos de R\$ 20 milhões. Muito pouco para o que seria o principal instrumento do desafio de redução das desigualdades raciais.É importante ressaltar que não está previsto, nas LDO ou nas LOA dos últimos anos, qualquer programa setorial que tenha por objetivo o combate às desigualdades raciais e suas causas. E sem programas, não há indicadores que permitam o acompanhamento das ações públicas.

A Política de Promoção de Igualdade Racial foi apresentada como diretriz nos dois últimos PPAs. No PPA 2003-2007, a estratégia de governo estava direcionada para a inclusão social e desconcentração de renda, por meio da dinamização do mercado de consumo de massa. As iniciativas que dariam forma a essa estratégia distribuíam em cinco dimensões: social, econômica, regional, ambiental e democrática, que se articulavam em torno de mega-objetivos, desdobrados em desafios a serem enfrentados por meio de programas compostos por ações conforme dispositivo normativo.

Tal desafio somente se desdobrou em dois programas, a saber: o da Gestão da Política de Igualdade Racial e o voltado às comunidades remanescentes de quilombos, o Brasil Quilombola.

O primeiro programa citado apresenta limites importantes, pois de acordo com o PPA, os programas de gestão não preveem a adoção de indicadores. Tais indicadores estão associados apenas aos programas finalísticos que são definidos setorialmente. Porém, como o desafio 'redução da desigualdade racial' não foi desmembrado em programas e/ou ações nos diferentes ministérios setoriais, não se constata uma concreta ação multissetorial para serem enfrentadas as desigualdades raciais no Brasil. Dessa forma, como não houve envolvimento efetivo dos demais ministérios na consecução de uma linha política de promoção da igualdade racial, ou seja, em face da ausência de programas setoriais, não foram previstos indicadores que balizassem, nas diferentes áreas, os resultados do programa e de suas ações.

De acordo com Theodoro (2010, p. 15) o Programa Brasil - Quilombola, que tem por objetivo “[...] coordenar as ações governamentais para as comunidades remanescentes de quilombo por meio de articulações transversais, setoriais e interinstitucionais, com ênfase na participação da sociedade civil [...]”, tornou-se o principal programa do Governo Federal no que tange a políticas direcionadas à população afrodescendente.

Entretanto, esse que seria o grande programa, e cujos recursos ultrapassariam aqueles previstos para a 
gestão da política de promoção da igualdade racial, foi objeto do maior contingenciamento entre todos os programas governamentais. De acordo com as informações consolidadas para o Orçamento Fiscal e da Seguridade Social, para o ano de 2005, entre todos os 92 programas sociais definidos no PPA 2004 -2007, o maior corte se deu justamente sobre esse que é, de fato, o único programa finalístico direcionado à comunidade negra.

Enquanto a média do total de recursos empenhados em relação ao que havia sido autorizado manteve-se em torno de 97,3\%, no caso do Brasil Quilombola, esse índice foi de $34,4 \%$. Ou seja, apenas $1 / 3$ dos recursos previstos foram efetivamente disponibilizados para o Programa. Nenhum outro programa governamental sofreu contingenciamento de tamanha natureza.

\section{Considerações finais}

A perspectiva de consolidação da Política de Promoção da Igualdade Racial, na atual conjuntura, carece de uma profunda revisão, sobretudo no que concerne ao conjunto de lacunas nas programações dos órgãos do PPA, a ausência de indicadores, no público alvo e mesmo na descrição dos objetivos das ações e não menos grave, a não vinculação de recursos para políticas voltadas a esse segmento da população.

Indefinições,falta de recursos, inexistência de programas e ações setoriais consolidados nos instrumentos de planejamento de governo, tudo isso consubstancia uma falta de identidade da máquina governamental com relação ao desafio de redução da desigualdade racial. As diretrizes foram postas; uma secretaria foi criada sem que seus objetivos se espelhassem no planejamento anual do governo e sem que programas e ações se efetivassem.

A Secretaria de Políticas de Promoção da Igualdade Racial - SEPPIR, enquanto órgão coordenador da política ainda não conseguiu, ao que parece, traçar estratégias para além das aproximações carismáticas cujo limite fica a cargo da simpatia do gestor da pasta; isso contraria frontalmente os instrumentos de acompanhamento da ação pública adequados às práticas de natureza transversal e multissetorial.

\section{Referências}

BOSCHETTI, Ivanete et al. Capitalismo em crise: política social e direitos. São Paulo: Cortez, 2010.

BOSCHETTI, Ivanete et al.. Política social: fundamentos e história. São Paulo: Cortez, 2006.

BRASIL. Lei $n^{o}$ 11.439, de 29 de dezembro de 2006. Disponível em: <http://www.planalto.gov.br/ccivil_03/_ ato2004-2006/2006/lei/l11439.htm.> Acesso em: $12 \mathrm{fev}$. 2012.

INSTITUTO DE PESQUISA ECONÔMICA E APLICADA. Políticas sociais: acompanhamento e análise. Brasília, v.18, 2011.

INSTITUTO DE PESQUISA ECONÔMICA E APLICADA. Políticas sociais: acompanhamento e análise. Brasília, v. 19, 2011.

JACCOUD, L.; BEGHIN. N. Desigualdades raciais no Brasil: um balanço da intervenção governamental. Brasília: Ipea, 2002.

PAIXÃO, Marcelo; CARVANO, Luiz M. (Org.). Relatório Anual das desigualdades raciais no Brasil: 2007-2008. Rio de Janeiro: Garamond, LAESER, Instituto de Economia, 2008.

SALVADOR, Evilásio. Fundo público e seguridade social no Brasil. São Paulo: Cortez, 2010.

SILVA JÚNIOR, Hédio. Direito Penal e Igualdade Racial Étnico-Racial. In: PIOVESAN, Flávia; SOUZA, Douglas de. Ordem jurídica e igualdade étnico - racial. Brasília: SEPPIR, 2006. p. 345-281.

SILVA, Tatiana Dias. Nota técnica $n .7$ - planejamento e financiamento das politicas para as mulheres: possibilidades para o Plano Plurianual 2012-2015. Brasília: Ipea, 2011.

SILVA, Tatiana et al. Nota técnica $n .7$ - planejamento $e$ financiamento das politicas de igualdade racial: possibilidades para o Plano Plurianual 2012-2015. Brasília: Ipea, 2011.

THEODORO, Mario. A problemática racial no Brasil: desigualdade ou racismo? Os perigos do racismo institucional. Brasília: Mimeo, 2011. 